\title{
Una reflexión sobre el aborto
}

\author{
A reflection on abortion
}

Alfredo Gaete

Gaete A. Una reflexión sobre el aborto . Evid Actual Pract Ambul. 2021;24(1):e002018.

\section{Estimada editora,}

Sin dudas el pasado año ha sido importante, se sancionó de la Ley 27.610, que regula la interrupción voluntaria del embarazo (IVE) ${ }^{1}$. Como sabemos, la posibilidad de terminar con una gestación ya existía, bajo ciertas condiciones, en nuestro país desde hace cien años. Lo que nuestros legisladores sancionaron es la facultad de hacerlo hasta la semana catorce y, luego de ese plazo, declaración jurada de violación mediante, o si está el peligro la vida o la salud integral -concepto amplio en sí mismo- de la persona gestante.

Escribo esta reflexión a título personal y no guiado por ninguna religión, ni de las tradicionales ni de las actuales, tampoco escribo recostado en ideologías que niegan la biología amañando conceptos en boga, que muchas veces considero motivados en proselitismo fácil e ideologizado.

Entonces, yendo al punto y sin eufemismos, el aborto es eliminar al concebido, es interrumpir de manera permanente y definitiva una vida única e irrepetible. No es distinto al recorrido vital que tuvimos todos nosotros, no hablamos de ninguna situación excepcional. Es una obviedad, los seres humanos comenzamos nuestra existencia de una manera que puede variar en algunos matices, pero esencialmente es la misma.

Dicha eliminación puede ocurrir por causas naturales o por interferencia externa.

Como médico no puedo entender a la vida sino como un fenómeno continuo en el cual es imposible distinguir compartimentos aislados. Muchas veces lo hacemos con fines didácticos y clasificatorios, es cierto, pero sabemos que el particular evento de existir tiene un principio que es unívoco y particularísimo, que es la unión de un óvulo y un espermatozoide, y que ese es el origen de la vida. Quienes están a favor del aborto minimizando los momentos tempranos de la gestación suelen decir que la vida no comienza con la concepción, que ocurre más tardíamente, o que está ligada a fenómenos de tipo embriológicos, lo que no dejan claro habitualmente es en qué momento ocurre.

Así se reconoce también en nuestra constitución nacional en última reforma -llevada a cabo en 1994- que ha incorporado con jerarquía constitucional una serie de tratados internacionales sobre derechos humanos aprobados por el Congreso de la Nación en virtud de las facultades conferidas por el art. 75, inc. 22 , del mencionado texto ${ }^{2}$. Estos tratados no sólo reconocen expresamente la inviolabilidad de la vida humana, sino que también quedó constitucionalmente determinado el preciso momento en el cual comienza la tutela del mismo: la fecundación (o en términos jurídicos: la concepción). Así se expresan, por ejemplo, la Convención Americana de Derechos Humanos (Pacto de San José de Costa Rica) y la Convención sobre los Derechos del Niño. Dicha circunstancia demuestra la recepción -por parte de nuestro ordenamiento jurídico- de la teoría científica que sostiene que se es persona desde la penetración del óvulo femenino por el espermatozoide masculino, cuestión ratificada por el art. 19 del Código Civil y Comercial de la Nación ${ }^{3}$.

No quiero irme en tecnicismos legales -que no son mi área de expertise- y citar leyes confundiendo anteriores conquistas femeninas y de derechos de las personas con lo principal a señalar: que el argumento central es de carácter científico, ético, humanitario y no solamente legal, puesto que puede entenderse que la ley diga todo lo contrario a lo entendido por la ciencia, lo cual no modifica el sustento científico-moral, pero sí nos interpela en tanto somos seres humanos primero y médicos después. La historia abunda y empacha de leyes tan legales como ilegítimas y antihumanas.

Como médicos sabemos perfectamente que la distinción entre la semana trece con cinco días y la catorce con dos días es absolutamente irrelevante y caprichosa en términos biológicos.

Como ser humano, no interpreto cómo una misma situación, -de un embarazo estamos hablando-, pueda ser en un caso un promotor de la dicha más absoluta y, en otro caso, una calamidad pasible de ser eliminada. En ambas situaciones estamos hablando de una vida humana, lo único que varía es un muy comprensible contexto quizá, pero si consideramos a la vida como el primero de los derechos humanos -que ciertamente lo es-, entramos en una contradicción insalvable.

Por otra parte, y más en mi calidad de médico, me resulta muy difícil de comprender y explicar un acto de atención de la salud al que entren dos vidas a una intervención y solo salga una, siendo la eliminación de una de ellas la intención de origen.

\section{No todo es lo mismo}

Creo que se cae en un error manifiesto poniendo en pie de igualdad la conquista de derechos como el voto femenino (Ley 13.100), la prevención de la violencia contra mujeres (Ley 26.485), los vinculados a la salud reproductiva (26.150) y demás leyes citadas en el artículo de Discacciati y colaboradoras ${ }^{4}$. Se hace una mezcla que lejos de aclarar las cosas, confunde. Son absolutamente distintos entre sí, opinables entre ellos y muy diferentes respecto del que aquí nos ocupa, el de la interrupción del embarazo.

Debemos considerar que los derechos que no son para todos dejan de ser derechos para transformarse en privilegios para algunos. Muchas de las leyes enumeradas encuadran allí, son producto de lobbys actuales, pero dejan afuera muchas necesidades acuciantes en beneficio de algunos y en mi opinión, de la política.

La igualdad debe ser ante la ley, no mediante la ley. Cualquiera sea la ley que intente uniformar y homogeneizar lo que no es asimilable terminará por crear diferencias y sesgos allí donde pretendía poner equidad. A mi juicio, son incomparables la ley de identidad de género con la ley de cupo que mencionan las autoras, atribuyéndolas a conquistas del feminismo, movimiento tan variopinto como, en algunos casos, caótico.

Pero volviendo al punto fundamental, la ley del aborto, dentro de las motivaciones que más frecuentemente se escuchan en favor de este. Tan escuchada como insolvente es aquella que menciona la inmadurez de los diferentes órganos, aparatos y sistemas del embrión o feto, como también la dependencia de la gestante, que sin ella esa vida en ciernes no tendría viabilidad ¿acaso no ocurre lo mismo luego del nacimiento, y por meses y años, luego? ¿acaso no hay maduración del sistema nervioso central muchas décadas extra-útero? ¿acaso no hay dependencia absoluta por parte del bebé de la gestante o de quien se haga cargo durante mucho tiempo postparto?

Citando al profesor Benegas Lynch, "podemos decir que el argumento que se esgrime de que el feto es inviable y dependiente de la madre, lo cual es cierto, del mismo modo que lo son

\footnotetext{
a Servicio de Medicina Familiar y Comunitaria, Hospital Italiano de Buenos Aires. alfredo.gaete@hospitalitaliano.org.ar
} 
los inválidos, los ancianos y los bebés recién nacidos, de lo cual no se sigue que se los pueda exterminar impunemente" 5 .

Lo es de igual manera aquel que pregona que el cuerpo es de la mujer y de allí la posibilidad de disponer de él como a ella le plazca. Médica y biológicamente conocemos que el producto de la gestación es otro ser, con genética distinta, potencialidad diferente y que, dejando fluir ese continuo maravilloso que es la vida en sus distintivas fases, estará entre nosotros cuando la biología lo permita de manera total e impertinentemente independiente de la voluntad de la gestante.

En esa línea es también frecuente escuchar que no es posible obligar a nadie a ser madre, "que la maternidad será deseada o no será", pues bien, esa mujer ya es madre independientemente de su deseo o voluntad de seguir adelante con ese embarazo. Otra vez, sarcásticamente, podríamos preguntarnos qué pasaría si ella no deseara con todas sus fuerzas y su negativa mental parir ese hijo. Sabemos que la vida se abriría paso a pesar de cualquier deseo; para terminarla es menester tomar una conducta activa, por lo tanto, no es obligar a nada a nadie, sino decidir interrumpir definitivamente un proceso biológico empezado por una pareja en una relación sexual.

Se suele también hablar de patriarcado, palabra tan mentada para distintos fines en estos días, arguyendo que si el embarazo lo cursaran los hombres sería legal hace tiempo. No lo veo así y tampoco la justicia. Sirva para ello saber que no hay juez que vaya a dispensar a ningún hombre de mantener a un hijo posterior a algún devaneo sexual "masculino/patriarcal" si la mujer quisiese proseguir ese embarazo, aun cuando hipotéticamente el hombre lo hubiese manifestado antes o inmediatamente posterior al acto sexual. Si el tan mentado patriarcado operara tan eficientemente en favor de los hombres no pasaría semejante cosa. Aclaro que no puedo estar más de acuerdo con la conducta judicial de imponer paternidad y hacer responsable a los progenitores por sus actos. Aquí no prima, solidariamente, aquello de que "la paternidad será deseada o no será".

Me dirán que los hombres muchas veces rehúyen y dificultan el cumplimiento de sus obligaciones, también es cierto y absolutamente repudiable.

Otra argumentación es la delicada situación del embarazo luego del crimen abyecto de violación de mujeres o, incluso peor, el de las niñas madres. Verdadero dilema ético, judicial y moral. No tengo respuestas para la situación más que estas dos preguntas ¿no es allí en donde hay que encerrar al violador de por vida? Y la fundamental ¿es moralmente aceptable solucionar un acto abominable con otro acto abominable?

Otro argumento es que la pobreza de la mujer o la familia que no desea un embarazo es suficiente como para que puedan decidir no agregar otro hijo más a los que ya tiene. Cínicamente podríamos responder que, si fuéramos a sacrificar a alguno, que sea al mayor de los que ya tiene, que lógicamente es el que más gasta y come. Claro que no es admisible semejante cosa, sí lo es instruir sobre cómo vivir una sexualidad responsable, educar, limitar y castigar la violencia sexual en las parejas.

También se dice y repite "el aborto es un problema eminentemente de salud pública". Anteriormente mencioné por qué no me parece cierto eso, el segar vidas humanas dentro del vientre materno no es meramente un problema de salud pública, es mucho más, ya que tiene costados legales, morales, éticos, sociales y hasta económicos. No debemos ser ilusos y soslayar el aparato abortista montado en distintos países que de "gratuito" tiene poco y nada, sea que lo pague el estado (contribuyentes, verbigracia) o los privados.

Como dice el sanitarista Miguel Schiavone, "el problema de fondo, la causa raíz que no se resuelve y se acrecienta es la pobreza; las muertes maternas, la mortalidad infantil, así como las causadas por tuberculosis, sífilis congénita, chagas, sarampión, solamente son los emergentes. Impusieron el aislamiento social reconociendo las graves falencias del sistema de salud pública, que no se resolvió ni se resolverá solamente con más camas de terapia intensiva o respiradores. Aprobaron asignaciones sociales de emergencia reconociendo las escandalosas cifras de pobreza" 6,7 .

Señala además el citado Dr. Schiavone "los últimos datos publicados por el Ministerio de Salud: 33 muertes anuales por aborto (no todas por aborto criminal), 7.262 muertes infantiles en menores de 5 años, 768 de estas muertes no recibieron atención medica durante su enfermedad o lesión, otras 14 fueron por desnutrición, 40 por diarrea infecciosa, 36.106 muertes por Covid (en aquel momento, hoy sabemos que muchos más). ¿Cuál es el problema de Salud Pública? Que hay subregistros, seguro, y en todas las patologías, ese es otro problema grave y prioritario. Sin embargo, como carga de enfermedad es baja, se mire con el indicador que sea" 6,7

\section{Sin pañuelos, ni verde ni celeste}

Me adelanto a la pregunta, por supuesto que no considero encarcelar a nadie por haberse realizado un aborto, eso sería injusto. Cosas muy diferentes son la despenalización y la legalización. Claro que entiendo que nadie llega a esta situación por gusto; al menos nadie en su sano juicio. También es cierto que hoy en día nadie, o solo en casos excepcionales, alguna mujer va presa por ese delito. Es otro ejemplo de cómo la ley y la realidad caminan muchas veces divorciadas y distantes.

Acompaño que haya un ordenamiento legal que saque de la clandestinidad la práctica que se hace desde siempre y por siempre, independientemente de las leyes y de los tiempos.

Finalmente, diré que luego de años de haber recibido la consulta de pacientes y parejas, familias enfrentadas al y por aborto y la dilemática situación, no encuentro motivos de festejo. Sí de reclamo y exhorto.

Como médico de familia no puedo dejar de pensar que el problema tiene otra amplitud y dimensiones, que estamos cortando otra vez el hilo por lo más delgado, por la indefensión de quienes no tienen voz, pero sí vida.

Considero que caemos en la trampa de festejar el fracaso, que desde un punto de vista sanitario amplio llegar al aborto es la claudicación -otra más- de nuestro ineficiente sistema de salud, que venimos desde hace muchos años ponderando la atención primaria sin darle ninguna jerarquía ni proyección en el tiempo. Solo porque queda bien decirlo y declamarlo, porque es políticamente correcto.

Lo cierto es que el equipo de salud que debería llegar a la prevención y promoción, o no está, o está mal remunerado y, lógicamente, se desmotiva y busca nuevos horizontes laborales; que las políticas y campañas no se mantienen en el tiempo o no llegan a sus poblaciones destinatarias, y que las provincias y regiones desfavorecidas de nuestro país siguen teniendo natalidad destinada a incrementar la pobreza -que cada vez es obscenamente mayor, aún con más gasto público- desde hace décadas. Aquella pobreza con que medran desde hace añares políticos de toda laya que un día suben al estrado a defender los derechos de los pobres y analfabetos, a quienes traicionan impunemente el resto del año. Las causas sobran, la política, la iglesia y la religión, la fragmentación y segmentación sanitaria, la ignorancia y la falta de elección del área de atención por los médicos y médicas jóvenes, sin olvidar por supuesto a las esenciales -y en tantas ocasiones aún más importantes- actividades no médicas del equipo de salud.

No se trata de aborto sí o aborto no, es una obviedad claro, me dirán, pero hay que dejarlo escrito. Escrito y en reclamo explícito de todos los aspectos que antes mencionara, dejando patente que cada aborto que se haga es el fracaso de un sistema del cual como médicos de familia y atención comunitaria somos responsables primarios, aunque no exclusivos, entendiendo que nuestra voz debería ir en ese sentido plural y no sectario.

¿Quiénes, si no salvo algunos de nosotros, podremos alzar la voz en lugar de los que no podrán hacerlo? 


\section{Bibliografía sugerida}

Alberto Benegas Lynch. Liberalismo para liberales. Buenos Aires, EMECÉ Ediciones, $1986^{8}$

Alberto Benegas Lynch. La libertad es respeto recíproco. Washington DC, Cato Institute, $2015^{9}$

Elías N. Badalassi. Análisis técnico-jurídico del proyecto de legalización del aborto $2020^{10}$
Nicolás Márquez, Agustín Laje. El libro negro de la nueva izquierda. Grupo Unión SRL, primera edición, 2016 ${ }^{11}$

Schiavone, Miguel A. "Legalización del aborto: fracaso de la salud pública”. Vida y Ética, 2018;19.2 ${ }^{12}$

Recibido el 30/01/2021 Aceptado el 03/02/2021 y Publicado el 18/02/2021.

\section{Referencias}

1. Argentina. Ministerio de Justicia y Derechos Humanos. Presidencia de la Nación. Acceso a la interrupción voluntaria del embarazo.; 2020. Available from: http://servicios.infoleg.gob.ar/infolegInternet/verNorma.do?id=346231.

2. Argentina. Ministerio de Justicia y Derechos Humanos. Ley 24.430. Constitución de la Nación Argentina. 1994;Available from: http://servicios.infoleg gob.ar/infoleglnternet/anexos/0-4999/804/norma.htm.

3. and ENB. Argentina. Ministerio de Justicia y Derechos Humanos. Análisis técnico-jurídico del proyecto de legalización del aborto 2020 2020. Available from: http://www.saij.gob.ar/elias-badalassi-analisis-tecnico-juridico-proyecto-legalizacion-aborto-2020-dacf200244-202011-24/123456789-0abc-defg4420-02fcanirtcod?q=\%20tema\%3Aaborto\&o=4\&f=Total\%7CTipo\%20de\%20Documento/Doctrina\%7CFecha\% 7COrganismo\%7CPublicaci\%F3.

4. Discacciati V, Epstein D, Musarella N, et al. En 2020, el aborto en Argentina salió de la clandestinidad. Evid Actual Pract Ambul. 2021;24(1):e002115. Available from: http://www.evidencia.org.ar/index.php/Evidencia/article/view/6910.

5. Benegas-Lynch A. El aborto y el respeto irrestricto por la vida de los otros; 2019. Available from: https://www.infobae.com/opinion/2019/11/30/elaborto-y-el-respeto-irrestricto-por-la-vida-de-los-otros/.

6. Sucri A. Aborto: ni por el bien de las mujeres, ni cuestión de salud pública; 2020. Available from: http://www.laprensa.com.ar/496094-Aborto-ni-porel-bien-de-las-mujeres-ni-cuestion-de-salud-publica-note.aspx.

7. Schiavone MA. Aborto: el ridículo argumento de un problema de Salud Pública; 2020. Available from: http://uca.edu.ar/es/la-universidad-institucional/ autoridades/mensajes-del-rector/aborto-el-ridiculo-argumento-de-un-problema-de-salud-publica.

8. Benegas-Lynch A. Liberalismo para liberales. Buenos Aires: EMECÉ Ediciones; 1986.

9. Benegas-Lynch A. La libertad es respeto recíproco. Washington DC: Cato Institute; 2015.

10. Elías N, Badalassi. Análisis técnico-jurídico del proyecto de legalización del aborto 2020; 2020. Available from: http://www.saij.gob.ar/eliasbadalassi-analisis-tecnico-juridico-proyecto-legalizacion-aborto-2020-dacf200244-2020-11-24/123456789-0abc-defg4420-02fcanirtcod?q= \%20tema\%3Aaborto\&o=4\&f=Total\%7CTipo\%20de\%20Documento/Doctrina\%7CFecha\%7COrganismo\%7CPublicaci\%F3.

11. Márquez N, Laje A. El libro negro de la nueva izquierda. Grupo Unión SRL; 2016.

12. Schiavone MA. Legalización del aborto: fracaso de la salud pública. Ponencia en la reunión de las comisiones de Salud, Justicia y Asuntos Constitucionales del Senado de la Nación, 24 de julio de 2018. Vida y Ética. 2018;19(2):203-206. 